\title{
CORPORALIDAD FEMENINA, AUTOESTIMA Y DISCURSO DE MODA: \\ UN ESTUDIO CUALITATIVO
}

\author{
Paloma Díaz Soloaga \\ pdiaz@ccinf.ucm.es \\ Universidad Complutense de Madrid \\ Patricia Núñez Gómez \\ patnu@hotmail.com \\ Universidad Complutense de Madrid
}

Recibido: 28-02-2012

Aceptado: 09-03-2012

\begin{abstract}
Resumen
El presente trabajo es el resultado de una investigación cualitativa realizada por las autoras, como parte de un proyecto mayor, sobre los estereotipos que los medios $-\mathrm{y}$ en particular la publicidad- ofrecen a la sociedad, así como la presión que ejercen sobre las mujeres. En él se recogen las conclusiones obtenidas tras la realización de un grupo de discusión y ocho entrevistas en profundidad a partir de la temática "corporalidad, autoestima y discurso de moda". El principal hallazgo de este artículo consiste en ofrecer un análisis razonado de las distintas perspectivas desde las cuales las mujeres afrontan su corporalidad y la relacionan con su autoestima, así como su percepción de los contenidos de los medios.
\end{abstract}

Palabras clave: Mujer, autoestima, corporalidad, moda, medios.

\begin{abstract}
This work is the result of a qualitative investigation carried out by the authors, as part of a wider project about the stereotypes that media - particularly advertising - offer to the society, as well as the pression on women. The conclusions reached during the conduction of a discussion group and eight deep interviews from the subject matter "corporality, selfesteem and fashion discourse" are brought together. The main finding of this article consists in offering a reasoned analysis of the different perspectives in which women face their corporality and relate it with their self-esteem, just like their perception of media contents.
\end{abstract}

Keywords: Woman, self-esteem, corporality, fashion, media. 


\section{Introducción}

El estudio de la influencia de los contenidos mediáticos en la auto-percepción del cuerpo femenino no es reciente en la literatura académica. Uno de los estudios más relevantes sobre este aspecto es el de Vickie R. Shields y Dawn Heinecken (2002): Measuring up. How advertising affects self-image. En su libro, las autoras resaltan la centralidad del mensaje publicitario en la creación de la identidad personal en la sociedad moderna y postmoderna;

"las imágenes de cuerpos ideales, mayoritariamente femeninos, son algunos de los mensajes más consistentes producidos por los anunciantes. La actual imagen estereotipada de un cuerpo perfecto responde a parámetros culturales occidentales y da forma a la expectativa de lo que es la corporalidad de género en el capitalismo global del siglo XXI" (Rutledge y Heinecken, 2002: 10).

En particular resaltan que la identidad sexual no sólo está configurada por la sexualidad biológica sino también por la influencia del contexto cultural y por el ideal social de masculinidad y feminidad transmitido, en gran medida, a través de los medios y más en concreto a través de la publicidad. Puede decirse que resulta alarmante la influencia que ejercen los contenidos publicitarios sobre la auto-percepción que las mujeres tienen de sí mismas.

\section{Algunas referencias sobre la autoestima}

Tras una revisión de la literatura se aprecia que los diversos acercamientos a la relación que existe entre los medios de comunicación y la autoestima suelen coincidir en sus afirmaciones, pero antes de entrar en dicha relación, conviene definir previamente lo que se entiende por autoestima. La autoestima se describe como una actitud positiva o negativa hacia uno mismo y aspectos como la apariencia física como la ropa que utilizamos, están relacionadas con ella (Rosenberg, 1989). Dicha actitud hacia uno mismo deriva de la imagen mental que tenemos sobre nuestro propio cuerpo aunque conlleva dos perspectivas, por un lado cómo nos vemos -la percepción que tenemos- y por otro cómo sentimos lo que vemos -cómo nos afecta-. La evaluación final que hacemos también puede verse influida por la ropa que llevamos y por la impresión que creemos vamos a producir en los otros, llegando a afectar incluso nuestro comportamiento hacia ellos (Ryan, 1991). La dimensión social es esencial en la autoestima; gracias a la aceptación como personas y como miembros del grupo, mejoramos en la autoestima; sin ella, la personalidad no logra crecer, ni el individuo puede desarrollar adecuadamente su psique.

Precisamente porque la persona es un ser relacional, la imagen corporal se desarrolla parcialmente como una función de la cultura en respuesta a los ideales estéticos del contexto. Por lo tanto se configura en comparación con la familia, los compañeros y las imágenes de los medios de comunicación y se realiza a menudo de manera inconsciente. Este proceso explicado 
a través de la teoría de la comparación formulada por Festinger en 1954, se fundamenta sobre la idea de que las personas comparan sus propias opiniones y habilidades con las de otros y dicha comparación afecta a su propia evaluación. Tendemos a compararnos con nuestros pares, pero eso no quiere decir que deban ser cercanos a nosotros; por ejemplo, de manera habitual lo hacemos con personas que aparecen en los medios de comunicación, aun sin conocerlas, y eso refuerza -sin ser conscientes- determinadas ideas sobre el atractivo. Las imágenes negativas del cuerpo son a menudo el resultado de un proceso de comparación social en el cual las discrepancias son percibidas entre uno mismo y el ideal cultural del atractivo (Donnellan et. al., 2005).

Por otra parte, la ropa que vestimos también transmite información sobre la persona que lo lleva, es un tipo de comunicación no verbal y de alguna manera, cada uno la utiliza como una manera de expresar sus convicciones, creencias, actitudes hacia la vida. Es fácil descubrir el modo en el que cada uno se entiende a sí mismo observando su vestimenta.

La autoestima ha sido un concepto bastante estudiado desde finales de los $90 \mathrm{y}$ principios del 2000 aplicado a campos de estudio como la comunicación, la vestimenta o la psicología (Kim, J.H. y Lennon, S.J. 2007). Dentro de las conclusiones más contundentes hay que señalar la relación que existe entre la baja autoestima -referida a la corporalidad y la depresión, los cambios de humor- (Donnellan et. al. 2005) y los desórdenes alimenticios, así como entre una baja autoestima y hojear revistas de moda.

Por último, conviene señalar que la autoestima se construye en el tiempo y sus efectos por lo tanto son temporales, es decir, pueden ser modificados (Richins, 1991).

\section{Efectos de los medios en la autoestima de las mujeres}

Diversos autores han tratado de estudiar los efectos que el consumo de medios puede tener sobre la percepción del cuerpo y la autoestima. Heinberg y Thompson (1995) por ejemplo, exploraron la internalización de los estereotipos sociales sobre la imagen del cuerpo a partir de un examen de anuncios televisivos. Para ello sometieron a dos grupos de mujeres a anuncios con y sin estereotipos femeninos. Los resultados del estudio mostraron que las mujeres expuestas a anuncios con estereotipos estaban menos satisfechas con su cuerpo que las que fueron expuestas a anuncios que no contenían imágenes femeninas estereotipadas.

Como ya se ha dicho, la mayor parte de los autores coinciden con Heinberg y Thompson, aunque también hay estudios que concluyen de diferente manera. Al mismo tiempo están de acuerdo en que la educación contribuiría a mejorar la satisfacción personal en cuanto a la percepción y aceptación de la apariencia física. Algunos en particular afirman que suministrar información a las mujeres sobre los efectos de la cosmética, la iluminación y la fotografía para retocar la imagen real, conduciría a que percibieran a las modelos como inapropiadas para la comparación con ellas mismas. Estos autores indican que 30 minutos de 
intervención psico-educativa para informar al público sobre las estrategias de marketing sería suficiente para obtener resultados positivos en este sentido (Posavac, Posavac, y Posavac 1998).

Otro aspecto interesante es la influencia de la edad en la autoestima de las mujeres en culturas occidentales ya que esta declina substancialmente durante la adolescencia cuando su apariencia corporal comienza a cambiar. Como es sabido, la imagen corporal se desarrolla en un contexto sociocultural determinado, y en las sociedades occidentales la abundancia de imágenes femeninas alejadas de la realidad es omnipresente (Clay, Vignoles, y Dittmar 2005). Ciertos autores indican que la relación entre la imagen corporal y la autoestima es especialmente problemática para niñas que crecen en el contexto desarrollado de la cultura de masas (Becker et al., 2002; Richins, 1991; Silverstein, Perdue, Peterson y Kelly, 1986) La adolescencia es un momento donde se forman impresiones sobre uno mismo, es una etapa de cambios y de búsqueda constante de autoafirmación de la identidad, por eso las imágenes emitidas por los medios de comunicación, que con frecuencia alteran la realidad para embellecerla, pueden generar disfunciones en la percepción del propio cuerpo, al compararlo con un ideal inalcanzable. Para estos autores la exposición a los medios puede hacer que se asuman ciertas actitudes socioculturales que pueden resultar negativas, aunque no todas las personas las internalizan de la misma manera. Del mismo modo los medios de comunicación no son la única variable que hace que las niñas asuman patrones sino que padres, amigos, colegio, otras instituciones y la sociedad en general tienen su parte en este proceso (Presnell, Bearman y Stice, 2004). También la actitud previa hacia su propio cuerpo influye en la internalización de los mensajes mediáticos. No tener en cuenta la importancia de estas variables a la hora de diseñar una investigación puede enmascarar los resultados obtenidos; por ejemplo, no es infrecuente el caso de que mujeres que no responden a los estándares sociales, estén contentas con su apariencia porque se valoran a sí mismas por otras cualidades. A eso nos referimos al decir que los resultados pueden ser erróneos o, al menos, engañosos.

Este enfoque está reforzado por otros autores que sostienen que la opinión que cada uno tiene de sí mismo está íntimamente relacionada con el contexto histórico, las condiciones socioculturales particulares y también con los medios (Markus y Nurius, 1986). En diferentes estudios se hace referencia a la importancia de la edad en el proceso de internalización de los estándares de belleza. Parece, que una satisfacción menor con el cuerpo es proporcional a la internalización de los valores estereotipados de belleza como puede ser la delgadez, por citar alguno (Stice et. al. 1994). Para otros autores, la exposición a los anuncios de este tipo contribuye a la depresión femenina y a bajos niveles de autoestima (Posavac, Posavac y Posavac, 1998; Posavac y Posavac, 2002).

Por otro lado, existe coherencia entre los autores que señalan el sexo como factor determinante: señalan que las mujeres son más vulnerables que los hombres en cuanto a satisfacer las expectativas sociales y a alcanzar un objetivo ideal de belleza. Según ellos, durante toda su vida procuran alcanzar los ideales de belleza que se marcan interiormente al 
mismo tiempo que, con frecuencia, quieren agradar a los demás (Saucier, 2004). Muchas niñas, por ejemplo, piensan que ser perfectas les hace ser más reconocidas por sus amigos (Posavac y Posavac, 2002).

Es indudable que muchos anuncios dirigidos a mujeres hacen referencia a la importancia de la delgadez - por ejemplo a través de la promoción de productos para realizar dietas- con mayor frecuencia que a los hombres. Estas percepciones tienen que ver con el diferente significado del éxito que desde los medios, pero también desde la sociedad, se atribuye al hombre y a la mujer: el éxito masculino se evalúa en términos de productividad y logros y el de la mujer en términos de belleza y atractivo corporal (Saucier, 2004).

Como los anuncios son conocidos por todo el mundo, los modelos representados hombres y mujeres- son considerados como representantes de toda la sociedad y de este modo validan los estereotipos sociales. Diríamos que de alguna manera contribuyen a resaltar lo que en la sociedad "es" lo masculino y lo femenino aunque en ocasiones precisamente vulneren dichas convicciones sociales para llamar la atención, sorprender o incluso escandalizar y de esa manera lograr notoriedad.

Entre los autores que estudiaron si la edad modifica el efecto que los medios ejercen sobre la autoestima encontramos dos enfoques. Por un lado están los que piensan que a mayor edad, menor influencia de los medios. Para estos autores, hay que señalar que también hombres y mujeres muestran comportamientos diferentes (Clarke y Griffin, 2007).

A medida que el varón madura le suele resultar más sencillo el reconocimiento de su propia identidad, sin embargo la mujer necesita realizar un mayor esfuerzo para aceptar su identidad puesto que se le suele relacionar con una pérdida de capacidad vinculada a su decadencia reproductiva. Por eso la solución habitual es la de camuflar y alterar los signos del paso del tiempo (Clarke y Griffin, 2007). En este sentido, para la mayoría de las mujeres de edad madura, las arrugas y el ganar peso les dificulta la identificación con el ideal de belleza propuesto desde los medios.

Como se ha mencionado anteriormente al hablar de la autoestima, a través del proceso de identificación, los individuos se comparan con modelos que tienen atributos positivos. Estos atributos refuerzan la identificación pero con aspectos externos como la anatomía, el vestido u otros. La mayor parte de los estudios señalan que con la edad, las mujeres tienden a compararse menos con los estereotipos mediáticos porque los modelos reflejados ya no son de su edad y por lo tanto la representatividad en los media es menor, y porque habitualmente la personalidad madura mira menos hacia fuera para reafirmarse (Ogle y Damhorst, 2005). Sin embargo, otros autores reflejan que la importancia de la apariencia no decrece con la edad (Kozar y Damhorst, 2009) precisamente porque en los patrones mediáticos y sociales, la vejez no está relacionada con el atractivo. En este mismo estudio, realizado con mujeres de 65 años y mayores, se concluye, por ejemplo, que el valor dado al uso de ropa de tendencia se considera necesario para ser atractivo socialmente y tener una vida social activa. Dicho con otras palabras, la apariencia y la moda influyen en la autoestima de manera indirecta a través de la participación 
social y las personas mayores la buscan como manera de seguir siendo aceptadas. En cualquier caso, también se puede concluir que los estudios muestran investigaciones a corto plazo y se echan en falta estudios a largo plazo.

En cuanto a la representación de la mujer en revistas generalistas y especializadas en moda, si lo comparamos con los estudios de Goffman en 1972, aunque pueda parecer que se ha experimentado una evolución positiva, de fondo la imagen femenina sigue estando distorsionada, manipulando su verdadera naturaleza, especialmente a través de la adjudicación de un papel sexual (Lindner, 2004). En este estudio y en otros, se muestra como los mensajes estereotipados de la mujer se encuentran muy a menudo en los anuncios y que se basan sobre todo en la objetualización de la mujer, mostrándola subordinada al hombre, desplazada de la vida cotidiana y en un claro desequilibrio en la representación del rol social que ocupa en la realidad. Los trabajos desarrollados por otros autores en revistas publicadas en nuestro país, reafirman estas conclusiones (Díaz Soloaga, Quintas Froufé y Muñiz 2010a; Díaz Soloaga, Muñiz y Froufé 2010b; Díaz Soloaga y Muñiz, 2012).

\section{Antecedentes y planteamiento del estudio cualitativo}

El presente estudio tiene su origen en un trabajo anterior desarrollado entre los años 2005 y 2010. Ese trabajo, sobre el discurso de las marcas moda creado a través del sistema publicitario, principalmente desde las revistas femeninas de alta gama, consistió en un análisis de contenido de más de 600 anuncios de marcas de moda (Díaz Soloaga y Muñiz, 2013; Díaz Soloaga, Quintas Froufé, y Muñiz, 2010a; Díaz Soloaga, Muñiz y Quintas Froufé, 2010b).

Como resultado se llegó a establecer una clasificación de 4 estereotipos femeninos que se repiten en la publicidad de marcas de moda de manera uniforme y previsible; entre estas representaciones de la mujer, como puede suponerse, se repiten con enorme frecuencia mujeres delgadas, con actitudes seductoras, sofisticadas o desafiantes, por señalar solo algunos rasgos.

Estos cuatro estereotipos responden a las siguientes descripciones:

- La "mujer moderna" que refleja los valores de triunfo, competitividad, éxito profesional, éxito afectivo, conquista, libertad y transgresión.

- La "mujer hedonista sensual" que refleja personajes en actitud de seducción, autocontemplación, y placer además de presentar mujeres atléticas -no extremadamente delgadas-.

- La "mujer frágil" presente en los anuncios con mujeres acostadas o recostadas, en actitud pasiva y reflejando sometimiento incluso tristeza, debilidad o languidez.

- La "mujer tradicional" resaltado por los valores de familia, amor, atención al hogar y maternidad. 
Gráfico 1: Presencia de Estereotipos en la muestra

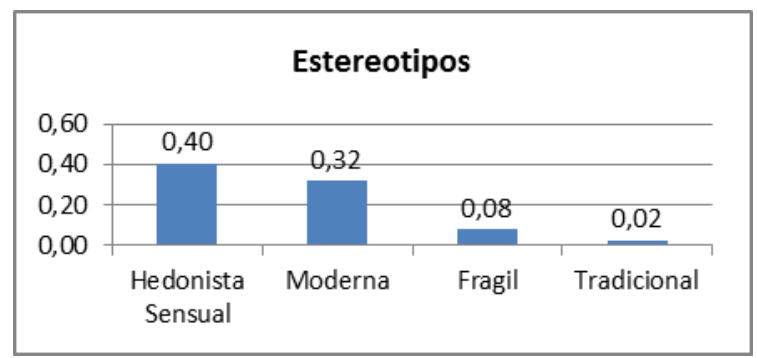

Elaboración propia

Como puede apreciarse en el gráfico, la presencia de los estereotipos en el conjunto de la muestra no es igual. El de mujer frágil es muy inferior al de mujer hedonista sensual y al de la mujer moderna; y el de mujer tradicional es prácticamente inexistente. Estos resultados evidencian la hegemonía de la mujer "hedonista y sensual" que incide en mostrarla como un objeto de placer. En términos generales, además, destaca su apariencia física, su capacidad de seducción así como la observación narcisista de su propia belleza. Este estereotipo refuerza y cristaliza el uso social de la mujer valorada siempre y cuando sea atractiva externamente. Estos datos parecen confirmar que las reclamaciones feministas de los años 70 que pretendían liberar a la mujer del entonces llamado yugo de la familia y la sumisión al varón han sido suplantadas por una hiper-sexualización del cuerpo femenino. Podría incluso decirse que ahora es la mujer la que voluntariamente se "somete" a dicho estereotipo que se impone clamorosamente en las revistas femeninas.

En este artículo se plantea una cuestión distinta, relativa a los efectos que los medios y en particular el discurso publicitario, ejerce sobre mujeres jóvenes. Dada la dificultad del objeto de estudio, se decidió utilizar técnicas cualitativas que permitieran crear un estado de la cuestión que posteriormente facilite la aplicación de otras técnicas complementarias, de corte cuantitativo.

Este trabajo significa una aproximación parcial al modo en que las mujeres construyen la imagen de su cuerpo y su relación con él respecto de las diferentes dimensiones que afectan a la presentación del yo en su vida cotidiana y ante sí mismas. Dicho con otras palabras, obtener una instantánea sobre el papel del cuerpo en relación consigo mismas, con su identidad y con su presentación en los escenarios de la vida cotidiana. Para su consecución realizó un estudio articulado en torno a los siguientes objetivos específicos:

- Determinar cuál es la relación de las mujeres participantes con la imagen de sí mismas, su auto-percepción y su autoestima.

- Conocer hasta qué punto y en qué momentos de los relatos sociales, el cuerpo juega un rol decisivo en la presentación de las mujeres en los distintos escenarios de su vida personal y profesional. 
- Precisar cuál es la procedencia de los modelos que las mujeres, reconocen o critican respecto de la percepción de su propio cuerpo.

- Establecer cuáles y cómo son dichos modelos, de acuerdo con el discurso de las mujeres, sus tipologías, límites y valoración discursiva.

- Analizar en qué medida esos modelos son socializados, por qué canales y cómo se ponen en relación con los discursos mediático-publicitarios.

\section{Metodología y diseño del estudio}

Para la consecución de los objetivos de la investigación, se realizó un estudio cualitativo mediante entrevistas en profundidad y grupos de discusión con mujeres jóvenes. Ambas técnicas permitieron tener una doble aproximación, especialmente relevante dados los objetivos que nos proponíamos:

- Por un lado, el grupo de discusión permite recoger los discursos sociales en un momento de producción e interacción aunque sea en un entorno artificial o provocado. Esta producción revela los discursos transversales y las tipologías de relato que ponen en juego los significantes que permiten seguir el hilo a los significados.

- Por otro, las entrevistas en profundidad permiten ver de qué manera las mujeres hacen suyos los discursos y modelos que circulan a nivel social y cómo se internalizan y se ponen por habla, al mismo tiempo que reúnen y fusionan las fisuras que los modelos corporales pueden suscitar en las entrevistadas. Esta aproximación es fundamental en un tema que afecta a dimensiones personales, sociales y culturales y que tiene que ver con la intimidad, la auto-percepción, la valoración y la re-presentación del yo.

Las entrevistas y el grupo fueron grabados en audio y transcritas literalmente para su análisis mediante técnicas de análisis del discurso. Previa a la exposición del análisis y los resultados, conviene resaltar algunos aspectos:

1. Las mujeres universitarias participantes en el estudio dieron por supuesto que hablar del cuerpo es hablar de su aspecto exterior. A pesar de que se hacen referencias difusas a la salud como condición general del cuerpo, el conjunto del relato gira en torno a la presentación del cuerpo ante los otros y ante una misma desde la perspectiva de la apariencia externa.

2. Esta manera de ver el propio cuerpo "desde fuera" lo sitúa como en un escenario desde el que se opera una especie de disociación entre el yo y el cuerpo. Dicha disociación se presenta como alienante porque el cuerpo se entiende como "otro" lo cual lógicamente influye en la elaboración e interpretación del yo así como en la 
presentación ante los demás. Llevado al extremo, puede decirse que no soy yo, sino otra persona.

3. La interpretación que se da al cuerpo posee modalidades; en realidad tiene varias perspectivas, a partir del lugar que ocupa dentro del relato en función de la presentación de la persona en un determinado entorno. De acuerdo con los resultados del estudio, se han identificado las siguientes formas de hablar y de entender el cuerpo:

- El cuerpo como sujeto

- El cuerpo como objeto

- El cuerpo como cualificación

A continuación se desglosarán las distintas dimensiones del cuerpo tal y como es percibido por las participantes en el estudio.

\section{El Cuerpo Como Sujeto}

Analizamos en primer lugar la presencia más obvia y abundante entre las participantes. El cuerpo aparece en sus recuentos como un sujeto situado, no como "algo", sino como "alguien". Es cierto que nuestra cultura el cuerpo se situaba a veces como sujeto de demanda, lo que era posible percibir en frases como:

"Hay que darle al cuerpo lo que pida"

"El cuerpo sabe lo que necesita"

Sin embargo, estas expresiones hechas, como tales, entendían el cuerpo como un sujeto neutro, lejano, cuyas necesidades -siempre en el plano físico, biológico, por así decirlovenían dadas por un funcionamiento independiente de nuestra voluntad. Entre nuestras participantes, ahora la corporeidad se presenta ante ellas casi como otra persona distinta, situada frente a ellas y exigiendo cuidados. Así por ejemplo de "lo que me pide el cuerpo" se ha pasado a frases como "no puedo abandonarme", "mi cuerpo me lo agradece muchísmo"...

La corporalidad aparece como en una dialéctica alienada, entre mi "yo" y "mi cuerpo", teniendo éste una preeminencia total en la que su demanda se impone ante la voluntad del yo.

El discurso de las participantes tiene una lógica de sometimiento del yo a las demandas de su cuerpo y, por lo tanto, el yo en su dimensión no corporal, no biológica, no se asocia con las cualidades "internas" sino con la apariencia física.

Las perífrasis del "sentirse a gusto con una misma" y sus expresiones circundantes son frecuentes y expresan precisamente esta superioridad de la demanda corporal, que trasciende las necesidades biológicas, pasando por varios estadios de compromiso: desde el cuidado por motivos de salud, de funcionalidad psico-física, de mantenerse "en buena forma", hasta la interiorización del sometimiento a la demanda corporal poniendo en juego todas las 
dimensiones de la personalidad (fuerza de voluntad, sujeción de la inmediata satisfacción del placer, concentración en el cuidado propio, etc.) al servicio de dicha demanda.

"Me siento más yo [cuando me cuido]"
"[Mi cuerpo] es lo que la gente ve de mí"
"Es que mi cuerpo soy yo, ¿sabes? No veo la diferencia..."

Cuando el cuerpo somete por completo las demás dimensiones de las participantes a su servicio, se llega a un protagonismo desmesurado, y el cuerpo parece que se independiza de la voluntad y del control de la mujer. En otras palabras el cuerpo adquiere funciones propias, como que se convierte en un ente independiente y se separa del yo "interno", de manera que puede suceder que el cuerpo se entienda como un oponente que escapa del control de la mujer, da sorpresas desagradables, impide la relación normal o feliz con el entorno, hace aparecer signos de descuido, de enfermedad o de imperfección:

"En cuanto me descuido..."

"No puedo dejarlo, porque en seguida me pone un kilo"

"Siempre, pero siempre, ¿no? he tenido este cuerpo. Y ya sé cómo reacciona"

En ese momento al cuerpo se le puede tener miedo, porque se temen sus reacciones, su descontrol, el no ser capaz de atender a su demanda. El cuerpo a veces puede ser una amenaza porque no está sometido al control de nadie, sino al contrario: controla y ejerce su demanda en detrimento del sujeto que le atiende. Pero el cuerpo puede adquirir también un carácter positivo y aceptable. Puede ser un sujeto adyuvante: compañero de viaje, mediador en el que se pone la confianza para presentarse ante otros. Es posible incluso que sea mejor que una misma, en casos extremos es lo mejor de una misma, o simplemente una misma en su mejor versión, y que exprese mejor lo que se pretende decir o hacer en el mundo.

\footnotetext{
"Llevo muchos años con él y siempre me ha ayudado. Por eso le cuido, jajaja..."

"Yo siempre he estado muy a gusto con él."

"Estoy convencida de que a mí mi cuerpo me ha ayudado mucho"
}

Esta frase textual expresa finalmente esta posición estructural en la que el cuerpo alcanza una posición más allá de la personificación, en la que las participantes van también más lejos de la simple disociación. El cuerpo se hace exterior, se hace otro y construye identidad desde el exterior de lo que podríamos denominar la metáfora personal.

El cuerpo deja, así, de ser una proyección de la personalidad, de un cierto yo interior, protagonista de la expresión de la personalidad pero también del alma, del espíritu trascendente. Es el cuerpo el que proyecta, construye y apuntala ese mundo interior. El yo se ha desplazado hacia el exterior en el discurso general de las participantes.

Para hacernos una idea de la potencia de esta posición del cuerpo, se puede recordar que recientemente se ha proyectado en televisión un anuncio en el que la mujer recibe un mail de su cuerpo con una demanda de cuidado. Es un ejemplo de esta disociación de la posición del yo 
como "interno". Pero esta posición del cuerpo en el discurso de las participantes no es única. El cuerpo puede aparecer, en el discurso de la misma persona, en otra posición distinta.

\section{El Cuerpo como Objeto}

Esta posición del cuerpo es más fácil de localizar, porque resulta más sencillo recurrir a la imagen metafórica del cuerpo como una máquina o un robot gobernado por el yo interno, consciente para presentarse socialmente ante el mundo. Este enfoque cultural sigue existiendo aunque parece ser que el cuerpo es considerado como objeto cuando se despieza en elementos aislados que deben ser objeto de mantenimiento, reparación o vigilancia específica.

"Mi cuerpo lo manejo yo"

"Es que siempre hay algo de tu cuerpo que no te gusta"

"En cuanto estoy dos días sin lavarme el pelo con mi champú, ya lo tengo como si me lo hubiera lavado con aceite"

En los grupos y entrevistas se habló del cuerpo desde un punto de vista genérico; mientras que la "partición" en zonas del cuerpo es más infrecuente. En este sentido, se habla de "desperfectos", de "reparaciones", de "cuidado constante", porque de lo contrario aparecen averías, abolladuras, imperfecciones que escapan al control en ciertas zonas que convierten a la persona en objeto de acciones de reconstrucción, de previsión, de vigilancia.

Cuidar el cuerpo, tiene aquí un matiz diferente puesto que el cuerpo es sujeto y aproxima a las metáforas del vehículo, de la habitación, en el sentido de objeto que hay que limpiar, decorar, mantener y vestir.

En la misma línea, el cuerpo entendido como un objeto, facilita o impide la relación de la persona con el entorno. Para las participantes es "lo primero que ven de mí" de manera que, además de una tarjeta de presentación, es una máscara no una proyección del yo, sino el yo en sentido lato: una es lo que perciben los demás, y esa percepción es, ante todo, corpórea.

El cuerpo es entendido no como una emanación de mis cualidades, defectos, sino la demostración de mis cualidades, de mis defectos, de mis anhelos o de mi personalidad entendida en sentido amplio. Si una persona muestra un cuerpo descuidado se interpreta que es descuidada; si se muestra un cuerpo atractivo, es atractiva y así es percibida por los demás; si el cuerpo está enfermo, o envejece, una está enferma o envejece; si el cuerpo no se muestra como se debe, podrá ser rechazada e incluso rechazarse a sí misma.

Es en este sentido en el que el cuerpo es el objeto que se ofrece al mundo, a los pares, en los entornos de presentación de la persona y, por eso, es la llave y la tarjeta de visita. Es lo que uno "es" porque es lo que los demás perciben. Lo que se me muestra fuera del espejo, lo que el yo percibe como la suma de las piezas que lo componen. Lo que se decora, se sutura o se arregla. En este contexto también aparece un cierto miedo al cuerpo, miedo a no poder controlar sus parámetros, a no poder llevar el timón, encarrilarlo como uno quiere. Podría 
decirse en términos de comparación literaria que la relación actual con el cuerpo se asemeja a Frankenstein frente a otros momentos históricos donde quizá había sido más cercana a la del Dr. Jeckyll o Dorian Grey.

\section{El Cuerpo cualificación}

En esta tercera perspectiva, el cuerpo está presente en el discurso de las participantes, como un conjunto de cualificaciones: se adorna, estropea, limpia o ensucia. Y además dice algo de una misma cuando se adorna. Así, los tatuajes o el piercing o la depilación corporal vendrían a ser cualificaciones del cuerpo:

"Es que mi cuerpo lo dice todo de mí"

"En el fondo, tu cuerpo una manera de... de decirles a los demás quién... bueno, lo que eres".

Esta posición del cuerpo en el discurso de las mujeres es compatible con su cosificación y con su personificación, con tal de que el cuerpo ya haya sido aceptado y puesto a punto. Una vez que la mujer haya asumido su cuerpo, su aspecto, como "normal". La normalidad, de hecho, es la primera palabra que aparece en las grabaciones de entrevistas y grupos. Es la primera respuesta a la pregunta por una misma, por su aspecto, por su corporalidad. En los grupos el término "normal" es un esfuerzo por socializar el pacto con el propio cuerpo:

"Todas somos normales"

"Yo soy normal, todos somos normales"

"Es que yo creo que todas las que estamos aquí somos normales, ¿no?"

La normalización significa que el cuerpo es lo que les pone en relación, en negociación $\mathrm{y}$, a veces, en conflicto, con su entorno personal y cotidiano.

"Cuando era más joven (sic) había muchas cosas que no me gustaban, pero ya llevamos juntos muchos años y me he acostumbrado. Yo creo que ahora me acepto mejor como soy. O sea, me cuido y tal, pero ya no me obsesiona"

Esta negociación, que sitúa a la mujer en la normalidad, acaba también como un pacto entre el yo y el ideal del yo. Se observan desgarros, evidentemente:

"Siempre quieres tener mejor tipo, (...), menos granitos, no sé... pero, vamos, que tampoco... Es que si no te da un chungo, ¿no?"

Con el paso del tiempo y en convivencia con la propia percepción, con lo que se entrega a los demás y que habla a una misma, se llega a una especie de compromiso. Aun con todo el ideal del yo se construye en gran medida empezando por el cuerpo. De tal modo que las cualificaciones que se asocian al cuerpo se convierten en un baremo moral llegando a afirmar 
que descuidar el cuerpo es descuidarse a sí mismo. Cultivar la salud es lo mismo que cultivar la belleza y la perfección moral. Someter el alma al cuerpo es ahora la virtud, el ideal. De ahí que se considere que no cuidar el cuerpo, dejarlo a su aire o no vigilar sus voliciones, sus apetitos, sus imperfecciones sea ahora una manera incorrecta de tratarse a uno mismo y -lo que es peor - de tratar a los demás. No puede sorprender que las personas feas, obesas, descuidadas, mal vestidas o simplemente no preocupadas por la moda sean discretamente rechazadas en la medida en que no han sometido su voluntad, que no han enfocado su virtud hacia su presentación física.

"Yo creo que alguien que no se cuida un poco es alguien que no cuida su vida, ¿sabes? O sea, no me refiero a ir siempre divina y tal. Pero no puedes ir por ahí de cualquier... Tienes que hacer un poquito el esfuerzo, ¿no?”

De ahí también que las descripciones que afectan al cuerpo busquen un compromiso entre la consideración del cuerpo como sujeto que demanda y que reclama un cuidado estricto, normalizado, regulado y la percepción de que se trata de un vehículo, de un objeto que hay que conservar y mantener, como los jardines expuestos al público, a la consideración de quienes miran. Porque no miran una fachada. Miran lo que uno es.

\section{Los medios de comunicación y el discurso sobre el cuerpo}

A primera vista, los medios de comunicación y la publicidad aparecen fuera del discurso espontáneo de las entrevistadas, es decir, bajo la consigna de que son un potente medio de presión para configurar exigencias no deseadas de la modelización a la que el cuerpo debe someterse. Se atribuye a los medios el estar en ese terreno de la amenaza, bien porque las informaciones desorientan sobre lo que es bueno o malo para el cuerpo, bien por la dificultad de ajustarse a modelos con los que se ha de estar de acuerdo en el plano del cuidado y la demanda del cuerpo, bien porque esas informaciones presionan aún más a las mujeres hacia un ideal del yo corporal que resulta difícil de conseguir.

No obstante, los medios tienen un papel ambivalente, en la medida en que gran parte de la información sobre las "demandas" del cuerpo provienen precisamente de ellos. Sus relatos suman y reflejan el discurso que hemos recogido entre las participantes, pero no procede, ni mucho menos, en exclusiva de la presión publicitaria o mediática. Los medios mediatizan, proponen, ofrecen herramientas para el "bricolaje" en el que las participantes se mueven, pero no imponen cuando se toman como fuente de información, de identificación y mostración de las demandas que el cuerpo hace a la mujer.

En este contexto, los análisis parecen indicar una cierta correspondencia entre el lugar de los medios (dentro de los cuales está incluido el discurso publicitario) y la forma de aparición del cuerpo. Los medios proporcionan por los cánones, las reglas a las que ajustarse respecto del cuidado, la apariencia y la solución de problemas del cuerpo. 
Esta presencia de los medios afecta a todas las dimensiones de la presentación de la mujer en sus círculos, y la información que ofrecen se abarca desde el vestido hasta la salud y el cuidado físico, pasando por la cosmética.

De nuevo en el discurso de las participantes, se busca la normalidad, la negociación entre el ideal marcado por la información y "el estar a gusto consigo misma", que cada uno expresa de manera que los medios indican también las normas de estilo - "tendencia"-que cada mujer personaliza de acuerdo con lo que se lleva: los dictados de las modas.

La mayoría de las mujeres participantes ven estos estilos como una manera de estar que permite la apropiación: cada una escoge una adaptación propia del estilo, pero lo hace precisamente de acuerdo con su percepción corporal o las variables que su "tipo" admite. En este sentido, revistas y sobre todo la publicidad ayudan a tener elementos para llegar a ese compromiso entre el cuerpo que se querría mostrar y el que se tiene y se muestra.

Se ha visto anteriormente que el cuerpo parece que escapa al control de la mujer, le da sorpresas o, incluso, dificulta su presentación en la vida de acuerdo con su ideal, y eso puede suscitar miedos como por ejemplo, el de perder el control sobre sí misma, el de no alcanzar la "normalidad", el "estilo propio", o "no estar a gusto con una misma", el miedo a perder la salud o la belleza. Cuando se habla de este aspecto las participantes culpan a los medios de comunicación.

Los medios son el arma principal, el instrumento de la máxima presión, la fuente de todas las exigencias externas que presionan, desde el cuerpo, desde la corporalidad, a la presentación del yo. Pueden asumir el papel de "auténtico enemigo", siendo el cuerpo obediente a sus designios, aunque es significativo que esto no se ha observado en los relatos analizados de manera clara.

Entre las participantes del estudio se niega que los medios tengan esa influencia sobre ellas, pero se admite que, cuando se es más joven o "cuando una está más obsesionada", su poder como sujeto prescriptor -“manipulador"—se hace muy notorio.

Es en este contexto cuando cuerpo (sujeto de demanda) y los medios de comunicación (sujeto de prescripción), se alían contra el control del cuerpo por parte del yo, cuando la persona siente que hace "algo mal", que no se cuida lo suficiente o que no llegará nunca a alcanzar los estereotipos que los medios proponen. Las participantes aseguran que:

"Hay que luchar contra eso: sabes que nunca vas a ser como esa modelo, o que no vas a ser alta... Pero a veces es muy difícil, porque te lo encuentras en todo, ¿no? ¡En todo!”

De ahí su rechazo hacia los medios prescriptores, aun cuando éstos, una vez negociada la aceptación del cuerpo, pueden no ser siempre culpables.

Como se ha mencionado, los medios no se citan de manera espontánea en relación al propio cuerpo, y curiosamente cuando el cuerpo es aceptado, el medio de comunicación -sobre todo el especializado-, se toma como el lugar donde las mujeres extraen los datos necesarios para un buen cuidado corporal, incluyendo la salud y la belleza. 
Pero también se toman en este caso como un corpus de instrucciones para la calidad de vida. Porque el cuerpo necesita un contexto en el que hasta la decoración y las recetas de cocina, la iluminación para leer o ver la televisión, los horarios para realizar las cosas cotidianas o los mejores lugares para descansar y recuperarse del cansancio físico y el estrés se explican en relación con el cuidado corporal. Todo ayuda a componer lo que se denomina el look, la imagen, y por tanto el mejor conjunto frente a una misma frente a los demás.

De modo que volvemos a encontrarnos, aquí, con que todo ayuda a la presentación corporal, lo que indica que no íbamos desencaminados. Todo tiene que ver con el bienestar corporal porque de él depende que la persona esté bien. El cuerpo se ha convertido, como decíamos, en un punto de convergencia que articula la calidad de vida y la imagen propia. Los medios asumen el papel de modelos simbólicos, como un manual de instrucciones:

"Hombre, en las revistas, en los anuncios y todo eso... te fijas. Luego ya, dices "esto sí" o "esto no", pero sí te fijas, sí"

En este sentido, se convierten en el referente, en el modelo "real" de la ficción que se va a representar. En otras palabras, tendríamos un doble papel de los medios:

1. Como "manual de instrucciones" o repertorio de uso de los elementos para que cada persona los utilice de acuerdo con unas normas de cumplimiento generales en cuanto a las tendencias, y específicas cuando se aplican a las diversas partes del cuerpo.

En este sentido admiten cualquier escenificación corporal que vaya desde la autopercepción del físico, el cuidado, la salud y el bienestar cosmético hasta el tipo de ropa que se lleva, no sólo durante una temporada, sino en los diversos ambientes u ocasiones. Su prescripción es siempre valorativa y así lo entienden las participantes.

2. Como sistema general de ordenación más allá de su uso concreto. Es decir: no de lo que es correcto "llevar o no llevar", "comer o no comer", etc. Sino qué se lleva, se come, se viste, en cada uno de los escenarios de presentación de la persona.

Con todo admite resistencias; "yo no soy de las que van a la moda", "yo no me trago todo" pero éstas, surgen como un esfuerzo por separarse de la imposición, no porque se desconozca o no se tenga en cuenta la norma.

En esta dialéctica los medios acaban, como el cuerpo, por tener una función normalizante para la mayoría de las participantes. Se toma como normal obtener información sobre las tendencias y los cuidados de los medios, se normaliza la relación con los medios en la medida en que se normaliza la relación con el propio cuerpo -lo que las participantes admiten que se consigue con el paso del tiempo y tras una negociación difícil-. Y, finalmente, normalizada, en el sentido de que se asume que la prescripción de los medios son en realidad una presión hacia el consumo así como la generalización de las tendencias. 
Esto no quiere decir que se borre por completo la crítica ni la desconfianza hacia la presión mediática, pero los casos de las pasarelas con modelos extremadamente delgadas, las propuestas de ser fashion victims y cualquier otro lugar corporal extremo se ve como al límite del escenario donde la corporalidad y los medios pueden llegar a ser dañinos para las mujeres.

En el estudio realizado los medios comparten esa "presunción ideológica" de moralidad asociada a su prescripción. No sólo instan al cuidado, sino que advierten de los peligros de no cuidarse; no sólo instan a una presentación corporal impecable, sino que castigan retóricamente a las mujeres que no cumplen este cometido que asocia salud, placer y belleza. En el discurso de las participantes esto aparece en forma de acatamiento:

“Te dicen lo que tienes que hacer para estar más a gusto..."

O en forma de rebelión y culpabilización impotente:

"Al final, quieras o no quieras, lo lees y dices "voy a probar". Al final caes"

De ahí que, también desde este punto de vista, estemos hablando, no sólo de un cambio en las relaciones entre el sujeto y su corporalidad sino también de una moral asociada que premia y castiga, que dicta y prohíbe. Mujeres y medios se encuentran en un entorno profundamente imbricado en el núcleo mismo de las producciones culturales. Estamos frente a un universo de sentido centrado en la imagen exterior de una manera multidimensional y profunda, en una cultura que está ahí, de la piel hacia fuera.

\section{Conclusiones}

El discurso de moda y belleza de los medios se sirve de un lenguaje que apela a la corporeidad de manera explícita e implícita, a través de imágenes y texto. Las mujeres, más sensibles que los varones en su mirada estética hacia el mundo, prestan gran atención a las propuestas mediáticas. Siendo las cosas así, la autoestima de las mujeres con frecuencia cifra su peso en el aspecto externo, con la intención de agradar y agradarse. Quizá la singularidad del momento actual puede ser que la identidad se argumenta más que en otras épocas en el "gustarse a uno mismo", por encima de darse o estar pendiente de los demás. La capacidad relacional de la persona, clave en el desarrollo de la identidad personal y la autoestima, se deja de lado, como si fuera menos importante que otros aspectos. El mejor ejemplo nos lo da la oposición entre la mirada solipsista y ausente de las modelos cuando posan y la mirada relacional de las personas reales.

Cuando durante el análisis realizado se observó la ubicuidad del término "cuerpo" viéndolo aparecer como sujeto, objeto y cualificación, empezamos a sospechar que algo 
ocurría con él. Ante la pregunta sobre sí mismas y su auto-percepción las mujeres hablaron del cuerpo inmediatamente, sin ninguna inducción. Y el hablar de esta manera suscitó a su vez un recuento que afecta a todas las dimensiones de su vida, en lo que tiene de presentación ante los demás y de reflexión acerca de sí mismas. No hablaron de hábitos, de cosmética o de vestido de forma espontánea, sino que hablaron de ellas, de sus pares, de su forma de estar en la universidad, en casa, con sus amigos y amigas, en su lugar de trabajo y aun en su propia habitación, frente al espejo. Esto indica, una vez más, que el cuerpo ocupa un lugar preeminente en nuestra cultura, entendido como punto articulante de la percepción propia y ajena, sobre el que se edifican las relaciones de las participantes en el estudio.

Es particularmente llamativa la independencia del cuerpo que se impone con frecuencia a la voluntad, pasando a ser el gran protagonista del mundo interior.

Estos resultados son coherentes con las enfermedades psicobiológicas que tanto preocupan en nuestra cultura en relación con el cuerpo. En estos casos seguramente el cuerpo ha asumido de tal manera el control, que el yo ya no puede ni siquiera percibir el propio cuerpo en deterioro. El espejo, y la imagen deformada que se percibe, mandan sobre todas las dimensiones de la persona enferma.

Como se ha visto el cuerpo también aparece como la representación de lo que uno es y como mediador que facilita o impide la relación de la persona con el entorno, y los medios de comunicación, junto con otras instancias educadoras, refuerzan el papel social, señala el ideal de belleza y marca las normas.

Resta decir que la autoestima se ve claramente afectada por el ideal de mujer que los medios y la publicidad proyectan de manera consciente o inconsciente. Al presentar a las mujeres con enorme frecuencia como objetos, cristalizan en ellas mismas el deseo natural de agradar a través de la belleza externa. Los medios conocen bien que el mejor mecanismo para incitar a la compra es la sensación de carencia, por este motivo, recrean la argumentación en torno a la necesidad de comprar para satisfacer una necesidad oculta o manifiesta. Si tenemos en cuenta que la autoestima se alimenta de la integración vital entre logros y fracasos, la aceptación de las propias limitaciones y la valoración personal por los éxitos en las distintas facetas de la vida (afectiva, profesional, social), nos damos cuenta que la publicidad asienta su lógica sobre la constante situación de "desventaja". Para muchas mujeres, la publicidad de moda y cosmética significa un constante recuerdo de lo "no conseguido" de lo "no alcanzado", del esfuerzo que se debe realizar para alcanzar una perfección externa, epidérmica y corporal. Por eso mismo quizá el mayor daño que los medios hacen a la autoestima de las mujeres no sea tanto el mostrar cuerpos esculturales imposibles de alcanzar por la inmensa mayoría, como la normalización del egocentrismo, de la mirada obsesiva hacia uno mismo y la concesión de una importancia excesiva al cuerpo en sí mismo, confundiendo a las mujeres en su búsqueda del equilibrio y la felicidad. 


\section{BIBLIOGRAFÍA}

- Becker, Anne E. et al. (2002): "Eating behaviours and attitudes following prolonged exposure to television among ethnic Fijian adolescent girls". En The British Journal of Psychiatry, $\mathrm{n}^{\circ}$ 180, pp. 509-514.

- Clarke, Laura Hurd y Griffin, Meridith (2007): "The body natural and the body unnatural: Beauty work and aging”. En Journal of Aging Studies, n 21, pp. 187-201.

- Clay, Daniel; Vignoles, Vivian L. y Dittmar, Helga (2005): "Body Image and Self-Esteem Among Adolescent Girls: Testing the Influence of Sociocultural Factors". En Journal of research on adolescence, Vol. 15, $\mathrm{n}^{\circ}$ 4, pp. 451-477.

- Díaz Soloaga, Paloma y Muñiz, Carlos (2013): En prensa. Women's portraits present in print fashion advertisements: a content analysis of Spanish fashion magazines from 2002 to 2009. Blackwell media content volume. En Angharad N. Valdivia (gen. ed.) y Sharon R. Mazzarella (ed.): The international encyclopedia of media studies. Vol. 3. Oxford, UK: Blackwell: Content and representation, pp. 74-94.

- Díaz Soloaga, Paloma; Quintas Froufé, Natalia y Muñiz, Carlos (2010a): "Cuerpos mediáticos versus cuerpos reales un estudio de la representación del cuerpo femenino en la publicidad de marcas de moda en España”. En ICONO, n 14, pp. 244-256.

- Díaz Soloaga, Paloma; Muñiz, Carlos y Quintas Froufé, Natalia (2010b): "La imagen femenina en la publicidad gráfica de moda: un análisis longitudinal de 2002 a 2008 ”. En Telos, $\mathrm{n}^{\circ} 86, \mathrm{pp} .122-133$.

- Donnellan, M. Brent et. al. (2005): "Low Self-Esteem Is Related to Aggression, Antisocial Behavior, and Delinquency”. En Psychological Science, nº 16, pp. 328-335.

- Festinger, Leon, (1954): “A theory of social comparison processes”. En Human Relations, $\mathrm{n}^{\mathrm{o}}$ 7, pp. 117-140.

- Goffman, Erving (1976): Gender Stereotypes. Washington, DC: The Society for the Anthropology of Visual Communication.

- Heinberg, Leslie J. y Thompson, J. Kevin (1995): "Body image and televised images of thinness and attractiveness: A controlled laboratory investigation”. En Journal of Social and Clinical Psychology, $\mathrm{n}^{\circ}$ 14, pp. 325-338.

- Kim, Jung-Hwan y Lennon, Sharron J. (2007): "Mass Media and Self-Esteem, Body Image, and Eating Disorder Tendencies". En Clothing and Textiles Research Journal, Vol. 25, n ${ }^{\circ}$ 1, pp. 3-23.

- Kozar, M. Joy y Damhorst, Mary Lynn (2009): "Comparison of the Ideal and Real Body as Women Age Relationships to Age Identity, Body Satisfaction and Importance, and Attention to Models in Advertising". En Clothing \& Textiles Research Journal, Vol. 27, n 3, pp. 197-210. 
- Lindner, Katharina (2004): "Images of Women in General Interest and Fashion Magazine Advertisements from 1955 to 2002”. En Sex Roles, Vol. 51, n 7/8, pp. 409-421.

- Markus, Hazel y Nurius, Paula (1986): "Possible selves”. En American Psychologist, Vol. 41, nº 9, pp. 954-969.

- Ogle, Jenniver Paff y Damhorst, Mary Lynn (2005): “Critical reflections on the body and related socio-cultural discourses at the midlife transition: An interpretive study of women's experiences". En Journal of Adult Development, Vol. 12, nº 1, pp. 1-18.

- Posavac, Heidi D.; Posavac, Steven S. y Posavac, Emil J. (1998): "Exposure to Media Images of Female Attractiveness and Concern with Body Weight Among Young Women". En Sex Roles, Vol. 38, n. 3/4, pp. 187-201.

- Posavac, Steven S. y Posavac, Heidi (2002): "Predictors of Women's Concern with Body wight: The roles of perceived Self-Media ideal discrepancies and Self Esteem. Eating Disorders". En The Journal of treatment \&prevention, Vol. 10, n 2, pp. 153-160.

- Presnell, Katherine; Bearman, Sarah K. y Stice, Erik (2004): "Risk factors for body dissatisfaction in adolescent boys and girls: A prospective study". En International Journal of eating disorders. Vol. 36, nº 4, pp. 389-401.

- Richins, Marsha L. (1991): "Social Comparison and the Idealized Images of Advertising". En Journal of Consumer Research, Inc, Vol. 18, nº 1, pp. 71-83.

- Rosenberg, Morris (1989): Society and the adolescent self-image. Revised Edition. Middeltown, CT: Wesleyan University Press.

- Ryan, Mary Shaw (1991): "Clothing: A study in human behavior". En Human Ecology Forum, Vol. 19, n 3, pp. 28-32.

- Rutledge, Vickie y Heinecken, Dawn (2002): Measuring Up: How Advertising Affects SelfImage. Philadelphia: University of Pennsylvania Press.

- Saucier, Maggi G. (2004): Midlife and beyond: Issues for aging women. En Journal of Counseling \&Development, $\mathrm{n}^{\circ} 82$, pp. 420-425.

- Shields, Vickie Rutledge y Heinecken, Dawn (2002): Measuring Up: How Advertising Affects Self-Image. Philadelphia: University of Pennsylvania Press.

- Silverstein, Brett; Perdue, Lauren; Peterson, Barbara y Kelly, Eileen (1986): "The role of the mass media in promoting a thin standard of bodily attractiveness for women". En Sex Roles, Vol. 14, nº 9/10, pp. 519-532.

- Stice, Eric et al. (1994): "Relation of media exposure to eating disorder symptomatology: An examination of media mechanisms". En Journal of Abnormal Psychology, Vol.103/4, pp. 836-840. 